\title{
Universal Exponential Amplification Confers Multilocus Detection of Mutation-Prone Virus
}

Yue Zhao, ${ }^{\dagger}$ Xiaoxing Fang, ${ }^{\dagger}$ Huahang Yu, Youlan Fu, and Yongxi Zhao*

Institute of Analytical Chemistry and Instrument for Life Science, The Key Laboratory of Biomedical Information Engineering of Ministry of Education, School of Life Science and Technology, Xi'an Jiaotong University, Xianning West Road, Xi'an, Shaanxi 710049, P. R. China

${ }^{*}$ To whom correspondence should be addressed. Tel: +86-029-82668908; Fax: +86-029-82668908; Email: yxzhao@mail.xjtu.edu.cn.

† Authors contributed equally to this work. 


\section{Contents}

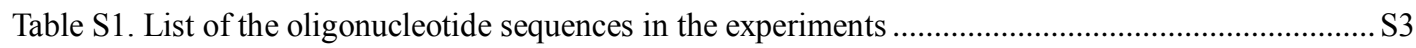

Figure S1. Gel electrophoresis analysis for the reaction efficiency …........................................... S6

Figure S2. The length optimization of repetitive sequences …..................................................... S7

Figure S3. The cleavage assay with polymerase and endonuclease …............................................ S7

Figure S4. The concentration optimization of endonuclease FEN1 .............................................. S8

Figure S5. The linear relationship between POI values and the logarithmic concentrations of target ....... S8

Figure S6. Real-time fluorescence analysis with and without loop primers ..................................... S9

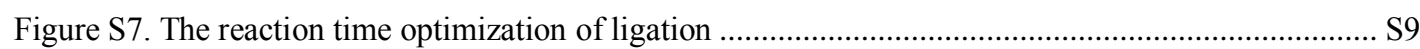

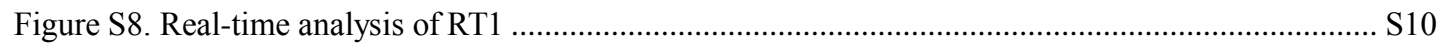

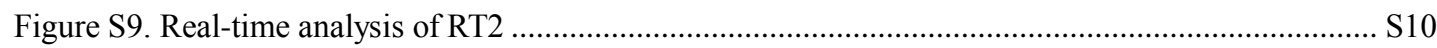

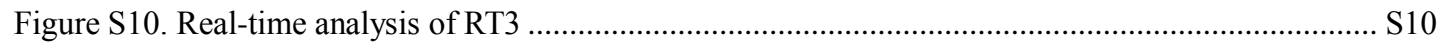

Figure S11. Multicolor signals obtained from various samples …................................................. S11

Figure S12. Gel electrophoresis analysis of multiplex LAMP ...................................................... S12

Figure S13. Multi-locus detection performance on mutated RNA .................................................... S13 
Table S1. List of the oligonucleotide sequences in the experiments

\begin{tabular}{|c|c|c|}
\hline Name & Sequences (5' to $\left.3^{\prime}\right)$ & Usage \\
\hline $\mathrm{FP}$ & $\begin{array}{l}\text { CGTGGCTTTCGAGTAGGGATGT-TTGATACGTTCCGGG } \\
\text { ATGTG }\end{array}$ & $\begin{array}{l}\text { Universal forward primer } \\
\left(\mathrm{F} 1-\mathrm{F} 2{ }^{\prime}\right)\end{array}$ \\
\hline $\mathrm{BP}$ & TTGGCGTAGTTCTCTGCCCCT-AGAAGGTTATTCAAGCCGCA & $\begin{array}{l}\text { Universal backward } \\
\text { primer } \\
\text { (B1'-B2) }\end{array}$ \\
\hline $\mathrm{LF}$ & TATACCGCGCTCGCATGA & $\begin{array}{l}\text { Universal forward loop } \\
\text { primer (LF) }\end{array}$ \\
\hline LB & TCGATTTAACAGGACACTTT & $\begin{array}{l}\text { Universal forward loop } \\
\text { primer (LB) }\end{array}$ \\
\hline DT1 & CCCTGTGGGTTTTACACTTAAAAACACAGAAAAA & DNA target sequence 1 \\
\hline RT1 & CCCUGUGGGUUUUACACUUAAAAACACAG & RNA target sequence 1 \\
\hline RT1-M1 & CCCUGUGGGUUUUCCACUUAAAAACACAG & $\begin{array}{l}\text { RNA target sequence } 1 \\
\text { with mutation } 1\end{array}$ \\
\hline RT1-M2 & CCCUGUGGGUUUUAÜACUUAAAAACACAG & $\begin{array}{l}\text { RNA target sequence } 1 \\
\text { with mutation } 2\end{array}$ \\
\hline RT2 & GUGAAAUGGUCAUGUGUGGCGGUUCACUA & RNA target sequence 2 \\
\hline RT3 & AAGGAAAUUUUGGGGACCAGGAACUAAUC & RNA target sequence 3 \\
\hline $\mathrm{T} 1$ & $\begin{array}{l}\text { GTGCTAATGACCCTGTGGGTTTTACACTTAAAAACACAGTC } \\
\text { TGTACCGTCTGCGGTATG }\end{array}$ & $\begin{array}{l}\text { Template used in the } \\
\text { cleavage assay of FEN1 }\end{array}$ \\
\hline P1 & CATACCGCAGACGGTACAGA & $\begin{array}{l}\text { Primer used in the } \\
\text { cleavage assay of FEN1 }\end{array}$ \\
\hline Probe1 & Cy5-CTGTGTTTTTAAGTGTAAAACCCACAGGG-Cy3 & $\begin{array}{l}\text { Reporter } 1 \text { used in the } \\
\text { cleavage assay of FEN1 }\end{array}$ \\
\hline Probe2 & $\begin{array}{l}\text { Су5-TTTTTTTTTTCTGTGTTTTTAAGTGTAAAACCCAC } \\
\text { AGGG-Су3 }\end{array}$ & $\begin{array}{l}\text { Reporter } 2 \text { used in the } \\
\text { cleavage assay of FEN1 }\end{array}$ \\
\hline Primer & $\begin{array}{l}\text { Cy5-CAGCTTCACTAGTAGGTTGTTCTAA-CCACAGAAGTGTT } \\
\text { AACAGAGG }\end{array}$ & $\begin{array}{l}\text { Cy5-labelled primer for } \\
\text { strand displacement } \\
\left(\mathrm{F} 1-\mathrm{F}^{\prime}\right)\end{array}$ \\
\hline Tem0 & $\begin{array}{l}\text { Су3-CAGCTTCACTAGTAGGTTGTTCTAA-CCTCTGTTAACAC } \\
\text { TTCTGTGG }\end{array}$ & $\begin{array}{l}\text { Cy3-labelled templates } \\
\text { for strand displacement } \\
\qquad(\mathrm{F} 1-\mathrm{F} 2-\mathrm{F} 2)\end{array}$ \\
\hline
\end{tabular}




\begin{tabular}{|c|c|c|}
\hline Tem6 & $\begin{array}{l}\text { Су3-CAGCTTCACTAGTAGGTTGTTCTAA-CCTCTGTTAACAC } \\
\text { TTCTGTGG-СCTCTG }\end{array}$ & \\
\hline Tem12 & $\begin{array}{l}\text { Су3-CAGCTTCACTAGTAGGTTGTTCTAA-CCTCTGTTAACAC } \\
\text { TTCTGTGG-CCTCTGTTAACA }\end{array}$ & \\
\hline Tem18 & $\begin{array}{l}\text { Cy3-CAGCTTCACTAGTAGGTTGTTCTAA-CCTCTGTTAACAC } \\
\text { TTCTGTGG-CCTCTGTTAACACTTCTG }\end{array}$ & \\
\hline Tem24 & $\begin{array}{l}\text { Су3-CAGCTTCACTAGTAGGTTGTTCTAA-CCTCTGTTAACAC } \\
\text { TTCTGTGG-CCTCTGTTAACACTTCTGTGGTTA }\end{array}$ & \\
\hline 3 -temp1-6 & $\begin{array}{l}\text { 5P-TAAAACCCACAGGG-CGTGGCTTTCGAGTAGGGATGT-CA } \\
\text { CATCCCGGAACGTATCAA-CACATC }\end{array}$ & \multirow{6}{*}{$\begin{array}{c}3 \text { ' fragment of template } 1 \\
\text { for universal } \\
\text { amplification } \\
\text { (Locus 1'-F1-F2-F2) }\end{array}$} \\
\hline 3 -temp1-9 & $\begin{array}{l}\text { 5P-TAAAACCCACAGGG-CGTGGCTTTCGAGTAGGGATGT-CA } \\
\text { CATCCCGGAACGTATCAA-CACATCCCG }\end{array}$ & \\
\hline 3-temp1-12 & $\begin{array}{l}\text { 5P-TAAAACCCACAGGG-CGTGGCTTTCGAGTAGGGATGT-CA } \\
\text { CATCCCGGAACGTATCAA-CACATCCCGGAA }\end{array}$ & \\
\hline 3-temp1-15 & $\begin{array}{l}\text { 5P-TAAAACCCACAGGG-CGTGGCTTTCGAGTAGGGATGT-CA } \\
\text { CATCCCGGAACGTATCAA-CACATCCCGGAACGT }\end{array}$ & \\
\hline 3-temp1-18 & $\begin{array}{l}\text { 5P-TAAAACCCACAGGG-CGTGGCTTTCGAGTAGGGATGT-CA } \\
\text { CATCCCGGAACGTATCAA-CACATCCCGGAACGTATC }\end{array}$ & \\
\hline 3-temp1-21 & $\begin{array}{l}\text { 5P-TAAAACCCACAGGG-CGTGGCTTTCGAGTAGGGATGT-CA } \\
\text { CATCCCGGAACGTATCAA-CACATCCCGGAACGTATCAAA }\end{array}$ & \\
\hline 5-temp1-6 & $\begin{array}{l}\text { GCCGCA-AGAAGGTTATTCAAGCCGCA-AGGGGCAGAGAAC } \\
\text { TACGCCAA-CTGTGTTTTTAAGTG }\end{array}$ & \multirow{6}{*}{$\begin{array}{c}\text { 5' fragment of template } 1 \\
\text { for universal } \\
\text { amplification } \\
\text { (B2-B2-B1-Locus 1') }\end{array}$} \\
\hline 5-temp1-9 & $\begin{array}{l}\text { CAAGCCGCA-AGAAGGTTATTCAAGCCGCA-AGGGGCAGAG } \\
\text { AACTACGCCAA-CTGTGTTTTTAAGTG }\end{array}$ & \\
\hline 5-temp1-12 & $\begin{array}{l}\text { ATTCAAGCCGCA-AGAAGGTTATTCAAGCCGCA-AGGGGCA } \\
\text { GAGAACTACGCCAA-CTGTGTTTTTAAGTG }\end{array}$ & \\
\hline 5-temp1-15 & $\begin{array}{l}\text { GTTATTCAAGCCGCA-AGAAGGTTATTCAAGCCGCA-AGGGG } \\
\text { CAGAGAACTACGCCAA-CTGTGTTTTTAAGTG }\end{array}$ & \\
\hline 5-temp1-18 & $\begin{array}{l}\text { AAGGTTATTCAAGCCGCA-AGAAGGTTATTCAAGCCGCA-AG } \\
\text { GGGCAGAGAACTACGCCAA-CTGTGTTTTTAAGTG }\end{array}$ & \\
\hline 5-temp1-21 & $\begin{array}{l}\text { TAGAAGGTTATTCAAGCCGCA-AGAAGGTTATTCAAGCCGC } \\
\text { A-AGGGGCAGAGAACTACGCCAA-CTGTGTTTTTAAGTG }\end{array}$ & \\
\hline 3-temp2-12 & $\begin{array}{l}\text { 5P-ATGACCATTTCAC-CGTGGCTTTCGAGTAGGGATGT-CAC } \\
\text { ATCCCGGAACGTATCAA-CACATCCCGGAA }\end{array}$ & $\begin{array}{c}3 \text { ' fragment of template } 2 \\
\text { for universal } \\
\text { amplification } \\
\text { (Locus 2'-F1-F2-F2) }\end{array}$ \\
\hline
\end{tabular}




\begin{tabular}{|c|c|c|}
\hline 5-temp2-12 & $\begin{array}{l}\text { ATTCAAGCCGCA-AGAAGGTTATTCAAGCCGCA-AGGGGCA } \\
\text { GAGAACTACGCCAA-TAGTGAACCGCCACAC }\end{array}$ & $\begin{array}{c}5^{\prime} \text { fragment of template } 2 \\
\text { for universal } \\
\text { amplification } \\
\text { (B2-B2-B1-Locus 2') }\end{array}$ \\
\hline 3-temp3-12 & $\begin{array}{l}\text { 5P-TCCCCAAAATTTCCTT-CGTGGCTTTCGAGTAGGGATGT- } \\
\text { CACATCCCGGAACGTATCAA-CACATCCCGGAA }\end{array}$ & $\begin{array}{c}3 \text { ' fragment of template } 3 \\
\text { for universal } \\
\text { amplification } \\
\text { (Locus 3'-F1-F2-F2) }\end{array}$ \\
\hline 5-temp3-12 & $\begin{array}{l}\text { ATTCAAGCCGCA-AGAAGGTTATTCAAGCCGCA-AGGGGCA } \\
\text { GAGAACTACGCCAA-GATTAGTTCCTGG }\end{array}$ & $\begin{array}{c}5^{\prime} \text { fragment of template } 3 \\
\text { for universal } \\
\text { amplification } \\
\text { (B2-B2-B1-Locus 3') }\end{array}$ \\
\hline 3-temp1-12L & $\begin{array}{l}\text { 5P-TAAAACCCACAGGG-CGTGGCTTTCGAGTAGGGATGT-TA } \\
\text { TACCGCGCTCGCATGA-CACATCCCGGAACGTATCAA-CACA } \\
\text { TCCCGGAA }\end{array}$ & $\begin{array}{l}\text { 3' fragment of template } 1 \\
\text { for universal } \\
\text { amplification with loop } \\
\text { primers } \\
\text { (Locus 1'-F1-LF-F2-F2) }\end{array}$ \\
\hline 5-temp1-12L & $\begin{array}{l}\text { ATTCAAGCCGCA-AGAAGGTTATTCAAGCCGCA- } \\
\text { AAAGTGTCCTGTTAAATCGA-AGGGGCAGAGAACTACGCCA } \\
\text { A-CTGTGTTTTTAAGTG }\end{array}$ & $\begin{array}{l}\text { 5' fragment of template } 1 \\
\text { for universal } \\
\text { amplification with loop } \\
\text { primers } \\
\text { (B2-B2-LB'-B1-Locus 1') }\end{array}$ \\
\hline Taqman 1 & Cy5-CTGTGTTTTTAAGTGTAAAACCCACAGGG-MGB & Reporter of target 1 \\
\hline Taqman 2 & Сy3-TAGTGAACCGCCACACATGACCATTTCAC-MGB & Reporter of target 2 \\
\hline Taqman 3 & FAM-AGTACGCTATTAACTATTAACGTACCTGT-MGB & Reporter of target 3 \\
\hline
\end{tabular}

Note: The letter 'P' indicates phosphate group. 'FAM', 'Cy3', 'Cy5' and 'MGB' indicates the fluorescent and quenching groups. The mutated nucleotides are underlined. 


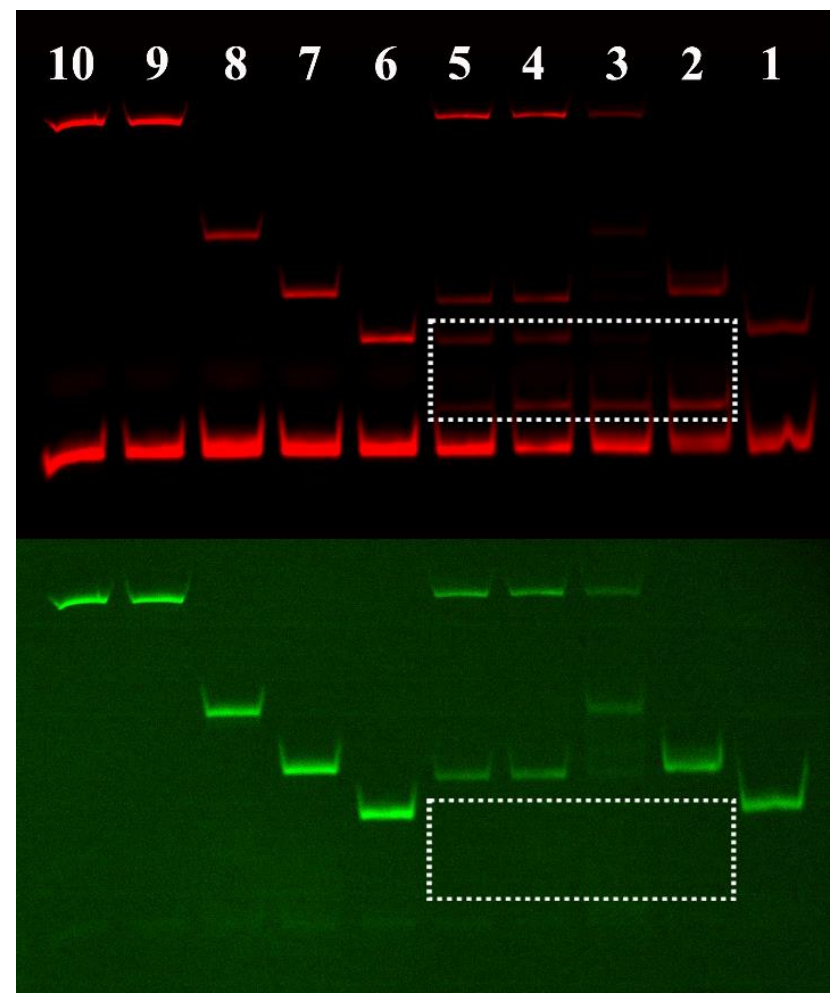

Figure S1. Gel electrophoresis analysis for the reaction efficiency of hybridization (lane 6-10) and strand displacement (lane 1-5). The upper image is obtained from the channel of Cy5, and the below is obtained from the channel of $\mathrm{Cy} 3$. The templates are added with repetitive sequences of 0 bp (lane 1, 6), 6bp (lane 2, 7), 12 bp (lane 3, 8), 18bp (lane 4, 9) and 24 bp (lane 5, 10). The bands of released single-strand DNA are denoted with the dashed box. All templates are labelled with Cy3 and the primers are labelled with Cy5. 


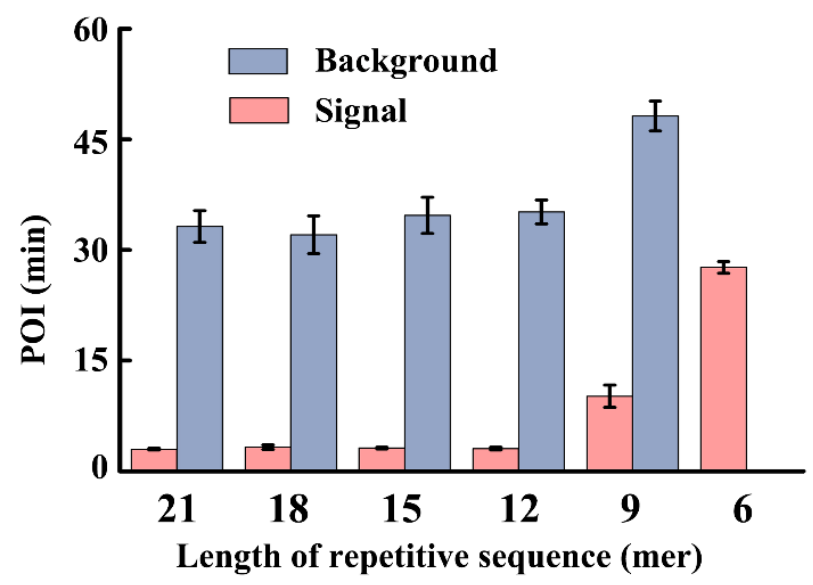

Figure S2. Optimization of the repetitive sequences at probe terminal in LAMP.

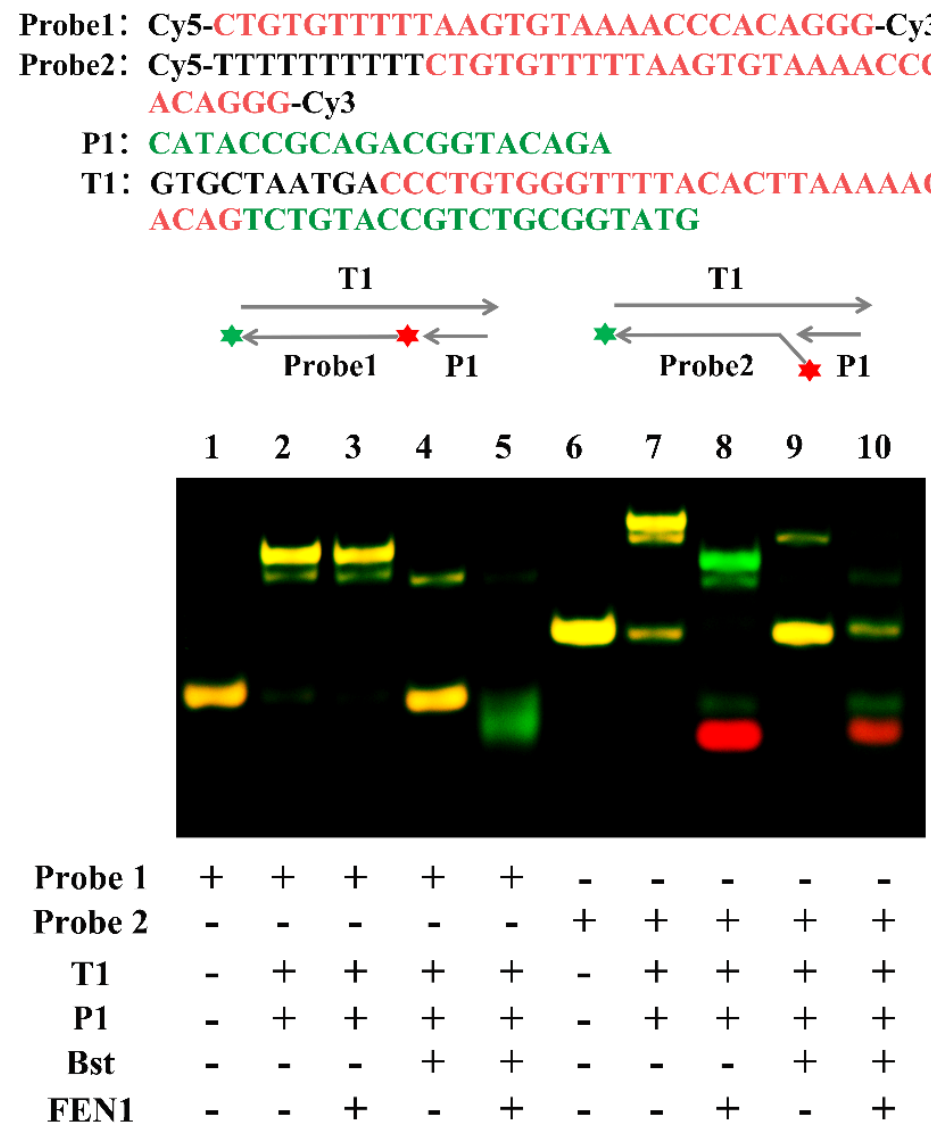

Figure S3. The cleavage assay with Bst2.0 WarmStart ${ }^{\circledR}$ DNA polymerase and FEN1 endonuclease. The plus and minus signs indicate the reaction with or without each component. The sequences of strands are shown and the same color indicates the respective complementary region. 


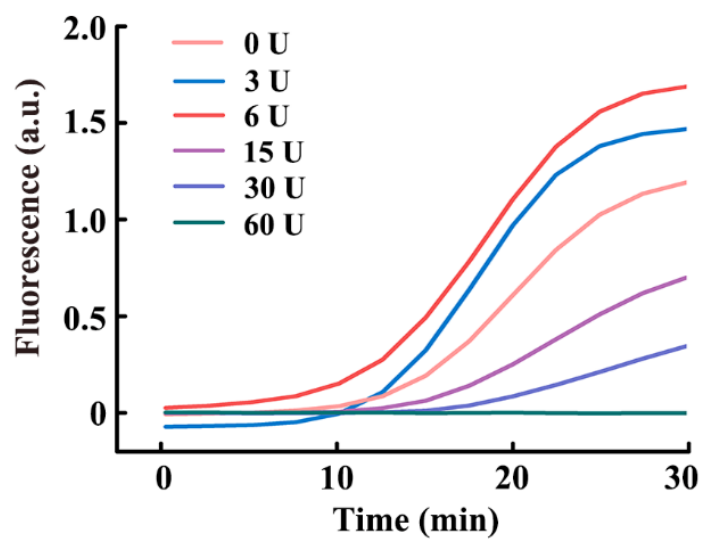

Figure S4. The concentration optimization of the endonuclease FEN1.

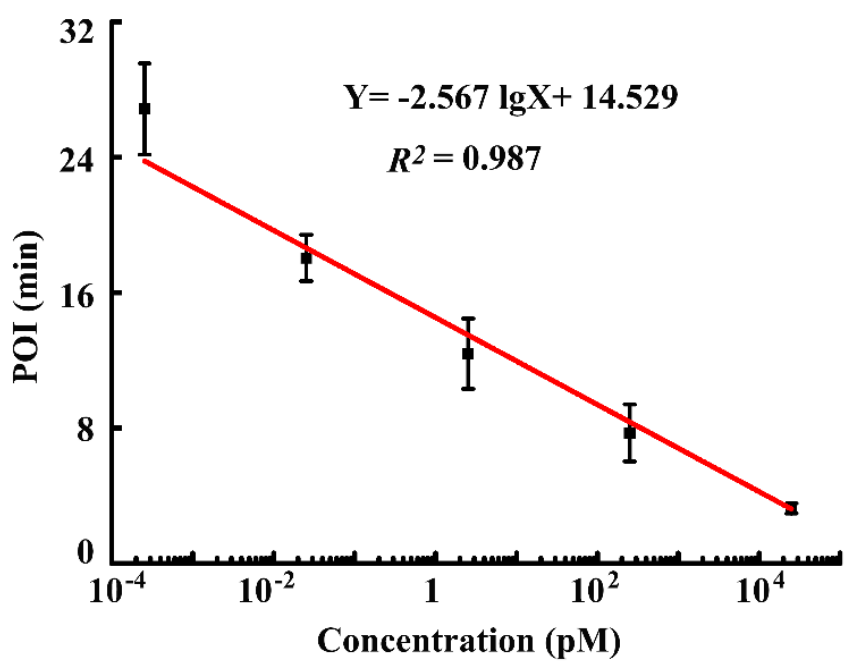

Figure S5. The linear relationship between POI values and the logarithmic concentrations of target RNA. 


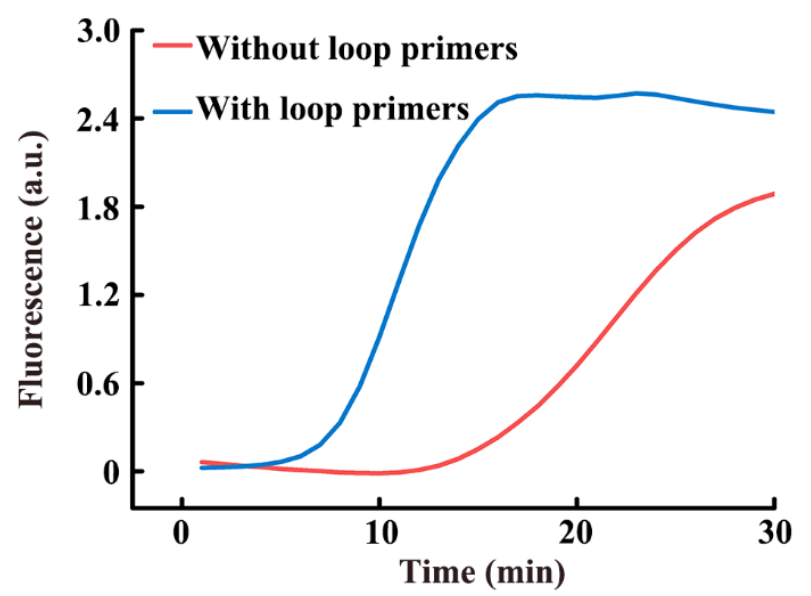

Figure S6. Real-time fluorescence analysis with and without loop primers ( $1 \mu \mathrm{M}$ each for $\mathrm{LF}$ and LB.)

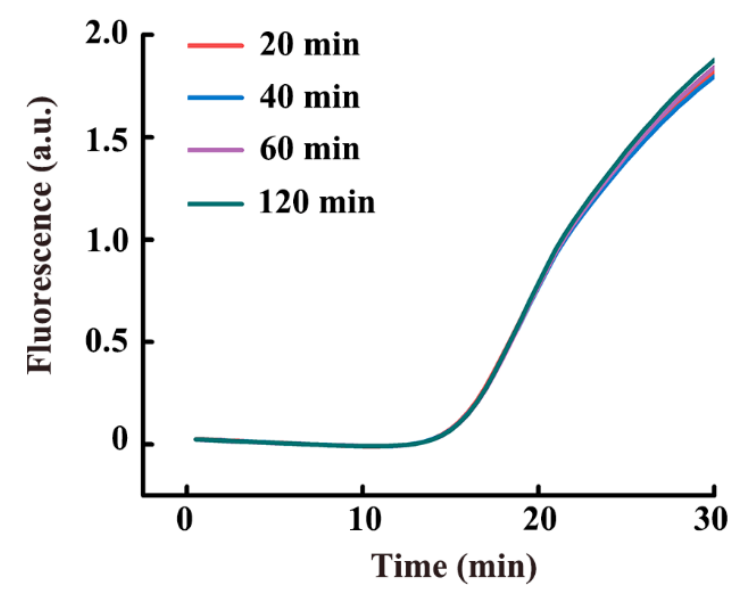

Figure S7. The reaction time optimization of the single-stranded template ligation. (The reaction mixture was heated at $95{ }^{\circ} \mathrm{C}$ for $3 \mathrm{~min}$. Then $50 \mathrm{U}$ SplintR Ligase was added into the mixture, and the reaction mixture was incubated at $37^{\circ} \mathrm{C}$.) 


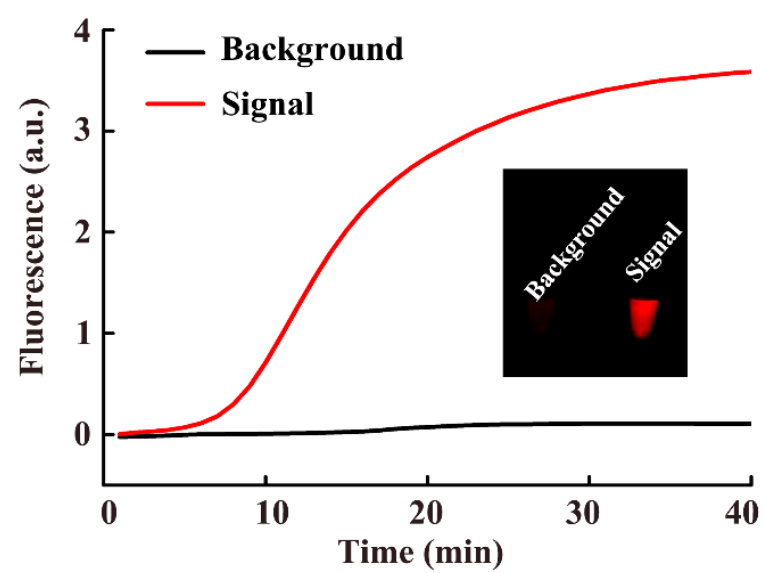

Figure S8. The real-time analysis of RT1 (locus 1) obtained from Cy5 channels, and the endpoint images are provided in the inset.

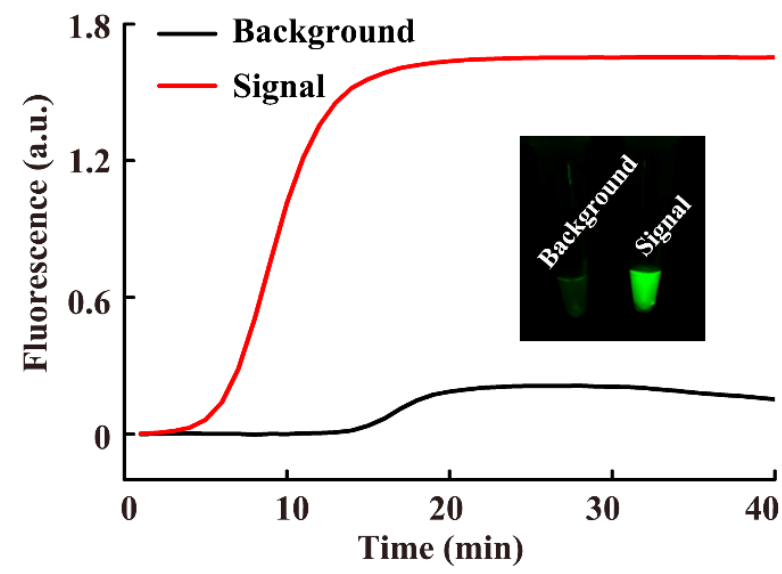

Figure S9. The real-time analysis of RT2 (locus 2) obtained from Cy3 channels, and the endpoint images are provided in the inset.

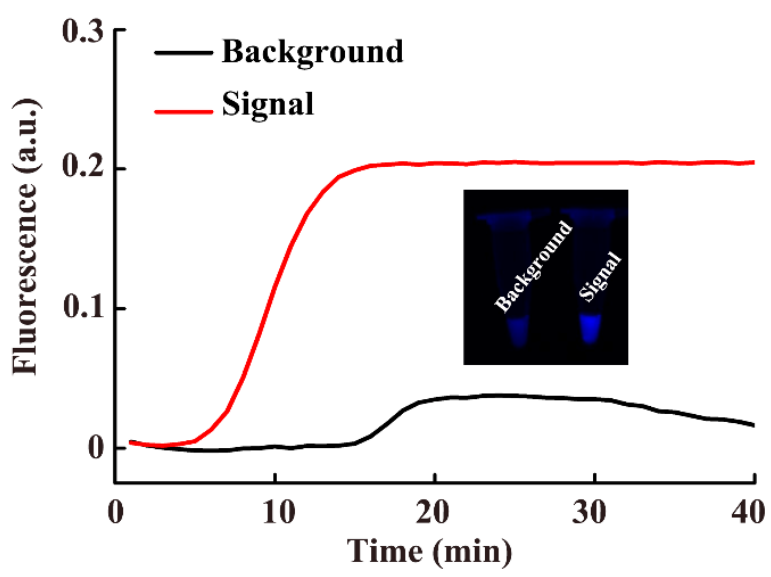

Figure S10. The real-time analysis of RT3 (locus 3) obtained from FAM channels, and the endpoint images are provided in the inset. 

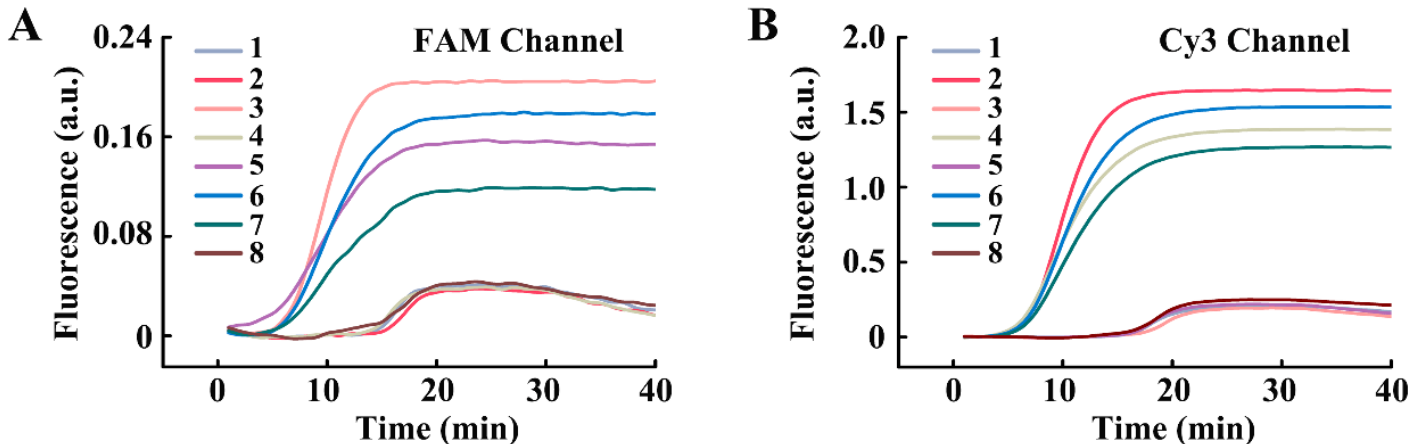

C

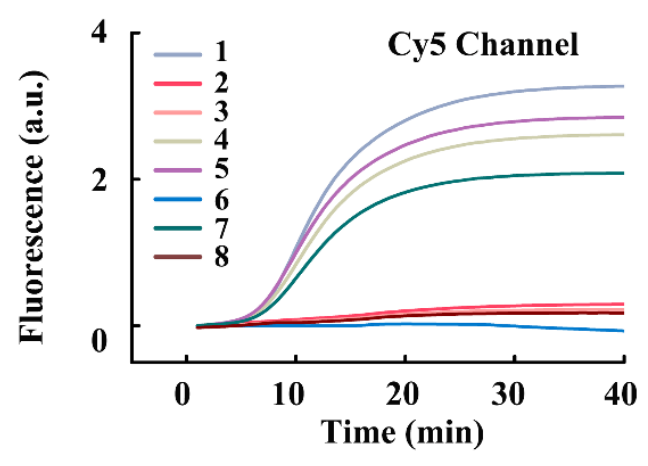

D

$\begin{array}{cccc} & \text { Locus 1 } & \text { Locus 2 } & \text { Locus 3 } \\ & & & \\ \mathbf{1} & + & - & - \\ \mathbf{2} & - & + & - \\ \mathbf{3} & - & - & + \\ \mathbf{4} & + & + & - \\ \mathbf{5} & + & - & + \\ \mathbf{6} & - & + & + \\ 7 & + & + & + \\ \mathbf{8} & - & - & -\end{array}$

Figure S11. The real-time fluorescent signals obtained from FAM (A), Cy3(B) and Cy5(C) channels of 8 kinds of spiked samples (D). 


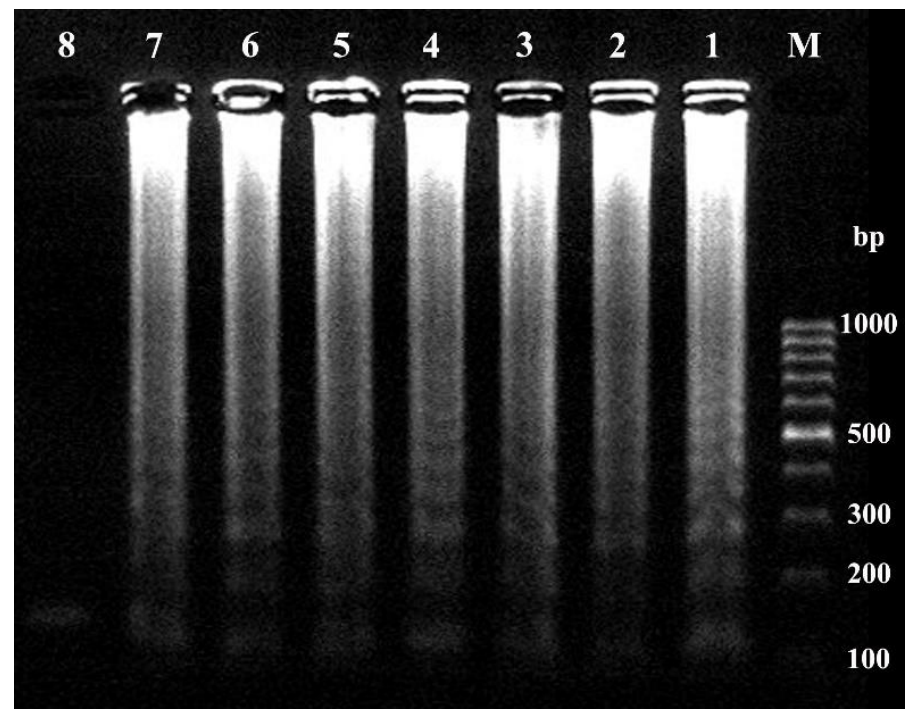

Figure S12. Gel electrophoresis analysis of the multiplex LAMP of 8 kinds of spiked samples.

Lane 1 is the sample containing gene locus 1 , lane 2 is the sample containing gene locus 2 , lane 3 is the sample containing gene locus 3, lane 4 is the sample containing gene locus 1 and locus 2, lane 5 is the sample containing gene locus 1 and locus 3 , lane 6 is the sample containing gene locus 2 and locus 3 , lane 7 is the sample containing gene locus 1 , locus 2 and locus 3 , lane 8 is the negative control without target locus. 


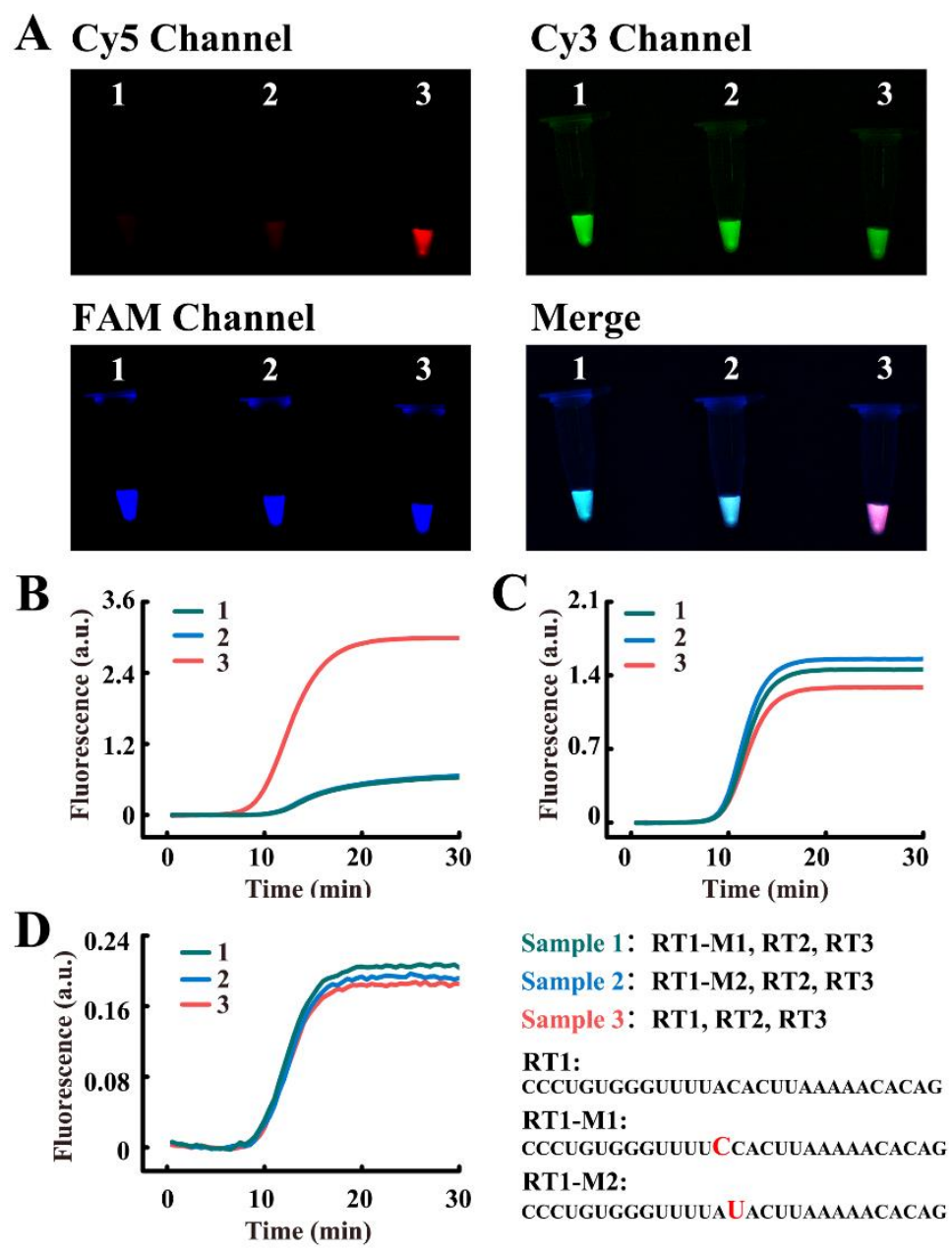

Figure S13. Multi-locus detection performance for mutated RNA. (A) Endpoint fluorescence visual detection under light of different wavelengths. The real-time fluorescent signals obtained from Cy5 (B), Cy3(C) and FAM(D) channels of 3 kinds of spiked samples. 